\title{
Benefícios dos alcaloides isoquinolínicos no sistema imune de garrotes alimentados com dieta de alta grão
}

Heloisa Godoi Bertagnon;,Angela Maria Reck, Alessandra Coelho Mayer, Bruna Artner, Desirre Pontarollo, Natali Schllemer, Mikael Neumann, Lucas Rigolin

Departamento de Medicina Veterinária, Universidade Estadual do Centro-Oeste (UNICENTRO), Guarapuava, PR, Brasil

*Autor correspondente

e-mail: hgodoi@usp.br

\section{Resumo}

Dietas de alto grão, embora aumentem a produtividade, em bovinos podem promover síndrome de acidose ruminal subaguda, caracterizada por acidose e inflamação ruminal, que desencadeiam uma cascata inflamatória que afeta o sistema imunológico e o desempenho animal. Estes efeitos foram minimizados em aves e suínos pelos alcaloides isoquinolinicos (IQ), e acredita-se que os efeitos anti-inflamatórios e imunomoduladores podem promover resultados similares em bovinos. Objetivou-se verificar se o IQ contido na suplementação (Sangrovit ${ }^{\circledR}$ RS, Phytobiotics Feed Additives Ltd., Eltville, Germany) reduz a inflamação causada pela dieta de alto grão em garrotes, bem como os efeitos adversos no sistema imune. Para tanto, 32 novilhos inteiros, $1 / 2$ sangue Angus-Nelore, $11 \pm 3$ meses, $365 \pm 10 \mathrm{~kg}$, inicialmente alimentados com silagem de milho, tiveram sua alimentação substituída gradativamente por dietas de alto grão (85\% de grãos de milho inteiros e 15\% de núcleo protéico-vitamínico-mineral, com monensina e virginiamicina) durante 15 dias. Durante esta adaptação, o grupo SAN ( $n=16)$ recebeu 4 g/animal/dia de Sangrovit ${ }^{\circledR}$ RS e o grupo CON ( $\mathrm{n}=16)$ não foi suplementado. Antes e após a troca da dieta, amostras de sangue foram colhidas para mensuração de função (fagocitose - F e metabolismo oxidativo - MO) e quimiotaxia (expressão de L - selectina) neutrofílica pela técnica de citometria de fluxo e para dosagem sérica de haptoglobina (HS) pela técnica de ELISA. Durante uma semana, antes e após a troca da dieta, os animais foram avaliados em relação à presença ou não de secreção nasal (SN). Pôde-se observar que a porcentagem de granulócitos realizando MO se manteve constante e estes não foram afetadas pelo IQ [MO(\%) - SAN - 58,3 $\pm 2,4$ e 73,2 \pm 6,7; CON 63,7 $\pm 3,1$ e 60,6 $\pm 6,3 ; P>0,1]$. Houve diminuição da porcentagem de granulócitos que fagocitaram,

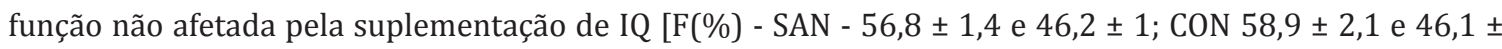
2,9; P < 0,04]. Os teores de HS se mantiveram constantes e também não foram afetados pelo IQ [HS(ug/mL) SAN - 112,8 \pm 7,5 e 11,8,0 \pm 7,5; CON $128 \pm$ 16,2 e 133,4 \pm 14,6; P > 0,1]. No CON houve aumento da migração 
neutrofílica, e não no grupo SAN, com diferença estatística entre os grupos (P = 0,04) [L- selectina (\%)SAN - 42,5 $\pm 1,9$ e 46,2 $\pm 4,9$ P > 0,1; CON 42,0 $\pm 2,6$ e 74,9 \pm 7,6 P = 0,0001]. Observou-se, ainda, aumento estatístico de $\mathrm{SN}$ em ambos os grupos, sendo este aumento estatisticamente menor no SAN do que no CON $(\mathrm{P}=0,003$ ) (SN - SAN - 3,8 $\pm 0,2$ e 5,3 $\pm 0,2 ; \mathrm{CON} 4,0 \pm 0,2$ e 6,9 $\pm 0,2 ; \mathrm{P}<0,04)$. Estes resultados indicam que o IQ foi capaz de reduzir a inflamação ruminal, o que resultou em menor migração neutrofílica para o rúmen, permitindo supor que mais neutrófilos permaneceram na circulação. Embora estivessem com sua função diminuída, por estarem em número maior, supõe-se que foram mais efetivos em manter os animais livres de afecções respiratórias, permitindo concluir que o IQ reduziu a inflamação ruminal e os efeitos adversos que a dieta causou no sistema imune. 